\title{
Friedreich's Ataxia 1976 - An Overview
}

\author{
A. BARBEAU
}

\begin{abstract}
SUMMARY: The prospective investigation of 50 cases of possible Friedreich's ataxia has permitted the clinical and biochemical delineation of the typical disease and an hypothesis on its pathogenesis. A tentative definition of the disorder could read: "Friedreich's ataxia is a progressive degenerative disease always inherited in an autosomal recessive fashion and characterized by a cardiomyopathy and a ganglioneuropathy with dying back phenomenon. It is probably secondary to a defect in the membrane transport of taurine and $\beta$-alanine andlor a defect in the regulation of pyruvate oxidation." The existence of two pathogenetically distinct distinct entities with the same phenotype is a strong possibility.
\end{abstract}

RÉSUMÉ: L'étude prospective de 50 patients possiblement atteints d'ataxie de Friedreich nous a permis de définir les composantes cliniques et biochimiques de la maladie typique et même d'émettre quelques hypothèses sur sa pathogénèse. Une définition temporaire pourrait se lire ainsi: ' $L$ 'ataxie de Friedreich est une maladie dégénérative progressive toujours transmise par voie autosomale récessive et caractérisée par une cardiomyopathie et une ganglioneuropathie marquée du phénomène dit de dying back. La maladie est probablement secondaire à un défaut dans le transport membranaire de la taurine et de la $\beta$-alanine etlou à un défaut dans la régulation de l'oxidation du pyruvate". Il existe une forte présomption en faveur de l'existence de 2 formes pathogénétiquement distincies de la maladie. formes se présentant avec le même phenotype.

From the Clinical Research Institute of Montreal and the Hôpital Hôtel-Dieu, Montreal.

Reprint requests for the complete supplement on Friedreich's ataxia to: Dr. André Barbeau, Clinical Research Institute of Montreal, 110 Pine Avenue West, Montreal H2W 1R7 Quebec, Canada.

\section{INTRODUCTION}

When this prospective survey of 50 cases of Friedreich's ataxia was planned, it was hoped that two main results would be forthcoming from the phase one approach: a redefinition of the absolute requirements for the diagnosis including the minimum constellation of symptoms and signs for early recognition, and a better understanding of the underlying biochemical substratum. This survey is the first attempt to systematically explore and record the main components of the clinical, paraclinical and biochemical structure of Friedreich's ataxia. We have studied 50 cases, of which 33 presented with all the cardinal features thought obligatory for diagnosis by a large panel of neurologists. In the course of this survey, we have confirmed some facts about the disease, but in numerous instances our findings differed from the literature or uncovered as yet unreported biochemical facets. The previous papers have tabulated these data and should be consulted for details. In the present overview we hope to collate and analyze the main "lignes de force" and to attempt some type of systematization of the findings in order to outline the goals of the subsequent phase two studies.

The extensive literature on Friedreich's ataxia and its variants, has been reviewed in extenso by Tyrer (1975) and the biochemical aspects summarized by Lubozynski and Roelofs (1975). We can limit our discussion to the differences between these reviews and the findings of the current survey which was concluded subsequent to these publications. The principal findings from the literature, as reviewed by Tyrer (1975), and our own conclu- sions are given in Table 1. Some important points touching the clinical presentation, electrophysiology and biochemistry must be mentioned:

\section{a) Clinical presentation of}

Friedreich's ataxia

A certain number of signs and symptoms appear in $100 \%$ of patients thought to be typical examples of the disease by a panel of neurologists. They are also the earliest signs and symptoms of the disease. Each of these signs (ataxia of limbs, unrelenting ataxia, speech disturbances, muscle weakness, decreased vibratory and position sense in the lower limbs, absent tendon reflexes in the lower limbs) must be considered a sine-qua-non for diagnosis. Because of their early appearance, they are most likely to reflect expressions of the primary pathogenic defect. A physiological "common denominator" analysis would indicate that this defect must involve, early in the disease, the posterior roots, mainly in the lumbar region, the posterior columns of the spinal cord and some midline nuclei of the brain-stem cerebellar system.

Other signs and symptoms, although frequent (more than $90 \%$ of cases) can be considered "progressive" in nature and appear later. This is the case for extensor plantar responses which are usually absent early in the disease when the deep tendon reflexes in the lower limbs are absent. This would indicate that lateral cortico-spinal tract damage is an extension of the disease process. Similarly, pes cavus and kyphoscoliosis are progressive and eventually functionally limiting, but the course of their evolution does not necessarily parallel the severity of other aspects of the disease. In a 
sense, the dystonic postures observed in the dorsal lumbar spine and foot regions are no different from those found in other disorders not associated with ataxia, but we believe they are, somehow, causally related to what eventually produces ataxia. It is important not to neglect the progressive nature of kyphoscoliosis because it will be responsible for severe pulmonary function restrictions that could have been prevented, or at least postponed, by surgical corrective methods.

Cardiomyopathy, usually in its hypertrophic form, is a cardinal feature of Friedreich's ataxia. By one assessment method or another it will reveal itself almost from the onset of the disease. However, it is variable in its clinical and electrical presentation and apparently does not parallel the severity of other aspects of the disease (such as ataxia or muscle weakness). Until late in the course of the ailment, the cardiopathy can remain asymptomatic. Moreover, hypertrophic cardiomyopathy although typical of Friedreich's ataxia and always present is not exclusive to that disease. It is difficult to imagine that the cardiomyopathy could be the cause of the ataxia, or the reverse. We believe that the two constant signs: ataxia and cardiomyopathy are manifestations of a common pathogenic defect, most probably inherited and biochemical in nature.

Despite earlier claims to the contrary, typical Friedreich's ataxia, including some of its variants, is always inherited as a Mendelian autosomal recessive disorder. The point is unexplored, but it seems that some hormonal factors may be active in modifying the age of onset, the severity and/or the expressivity of the illness. Women appear to show symptoms earlier than men, and often (at least in our series) have a more serious course, with frequent and severe disturbances in glucose metabolism.

b) Paraclinical observations are of importance in the diagnosis and recognition of Friedreich's ataxia. There are a number of vecto- and echo-cardiographic findings which
INTERRELATIONSHIPS OBSERVED IN FRIEDREICH'S ATAXIA

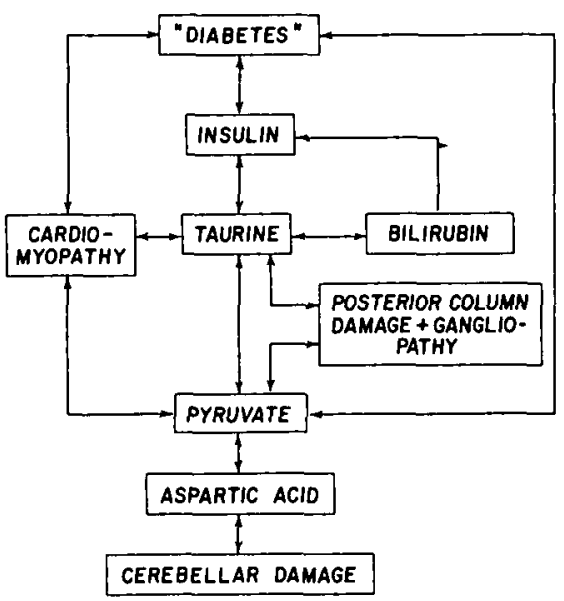

Figure 1 -Possible relationships in Friedreich's ataxia.

are frequent in this disease. Since many of these (such as the presence of abnormal vectocardiographic loops which we have called patterns $\mathrm{A}+\mathrm{B}$ and $\mathrm{A}+\mathrm{C}$ had not been reported before, it is too early to tell whether they are characteristic or pathognomonic of Friedreich's ataxia. Nevertheless, they are sufficiently frequent to warrant further investigations and observations. As they are noninvasive techniques we think both vectocardiograms and echo-cardiograms should become a standard feature of the investigation of ataxic syndromes and of preclinical detection of Friedreich's ataxia.

Although electroencephalography has not been useful in the differential diagnosis of ataxic disorders, nerve conduction studies proved to be of considerable help. All typical Friedreich's ataxia patients show a complete absence of sensory nerve conduction (as measured by evoked potentials) in the lower limbs early in the disease with a marked decrease in the upper limbs. Motor conduction velocities are normal or at the lower limits of normal. This indicates that the reflex arc is impaired by the primary pathological process which is most likely situated first in the posterior roots and ganglia of the lumbar region of the spinal cord. As will be seen, the biochemical and histological findings in Friedreich's ataxia are compatible with a gang- lioneuropathy manifesting as a dying back phenomenon (Cavanagh, 1964).

c) Biochemical Observations in the course of the survey, albeit incomplete and fragmentary, may be of great importance for the eventual understanding of the pathogenesis of Friedreich's ataxia. The great number of seemingly unrelated facts deserves an attempt at synthesis. It may be possible to discern which findings are primary, and which are secondary. Figure 1 shows the complex interrelationships which could be studied from the presently known biochemical facts which were listed in Table 1 and discussed. The major problem is to determine which of these findings are the genetically determined primary biochemical defects, and which are secondary or consequences of the disease. From our results and observations, at the end of 1976, four dysfunctions appear eligible for the primary role in Friedreich's ataxia:

(i) A defect in hepatic cell function

(ii) A defect in insulin metabolism

(iii) A defect in pyruvate metabolism

(iv) $A$ defect in the transport of taurine and/or $\beta$-alanine, generalized or limited to the kidney.

Each of these pathogenetic hypothesis shall be considered:

(1) Bilirubin Metabolism. To explain the presence of frequent unconjugated bilirubinemia in Friedreich's ataxia is to inquire whether this finding is the coincidental addition of a Gilbert's disease gene to that of Friedreich's ataxia or an unusual secondary manifestation of the basic disease process. Gilbert's disease (constitutional hepatic dysfunction, idiopathic unconjugated hyperbilirubinemia) is common in any population and is usually transmitted as an autosomal dominant character (Powell et al., 1967). We have not studied a sufficient number of the parents of our ataxic subjects to know if the defect is transmitted in dominant form in our patients. Of the 382 control subjects tested, a total of $6(1.6 \%)$ had total bilirubin values above $1.0 \mathrm{mg} \%$ and 22 above $0.8 \mathrm{mg} \%$ (6\%). These figures probably give a fair indication of the max- 
imum prevalence of Gilbert's disease in a French Canadian population. In our cases of Friedreich's ataxia, we found $20 \%$ with levels of total bilirubin above $1.0 \mathrm{mg} \%$ and $28 \%$ with levels above $0.8 \mathrm{mg} \%$. Such a concentration could be due to selection by kindreds of our patients. High bilirubin values were found in 7 of the 20 apparently unrelated kindreds studied, which would be an extremely unlikely chance event.

The pathogenesis of Gilbert's disease is unknown. Recent studies would implicate a transport defect into the hepatic cell and possibly a deficiency in the conjugation mechanism (Powell et al., 1967). We do not know if a similar modification is present in some of our patients. However, we are fairly certain that gross hepatic functions are not impaired in these patients. Whether mitochondrial defects are present is not apparent, the only abnormality noted being the high output of ornithine. Finally, because of the marked variability from day to day, we are not certain whether the bilirubin levels may not be abnormal in all cases, under the proper conditions. However, it is safe to state that

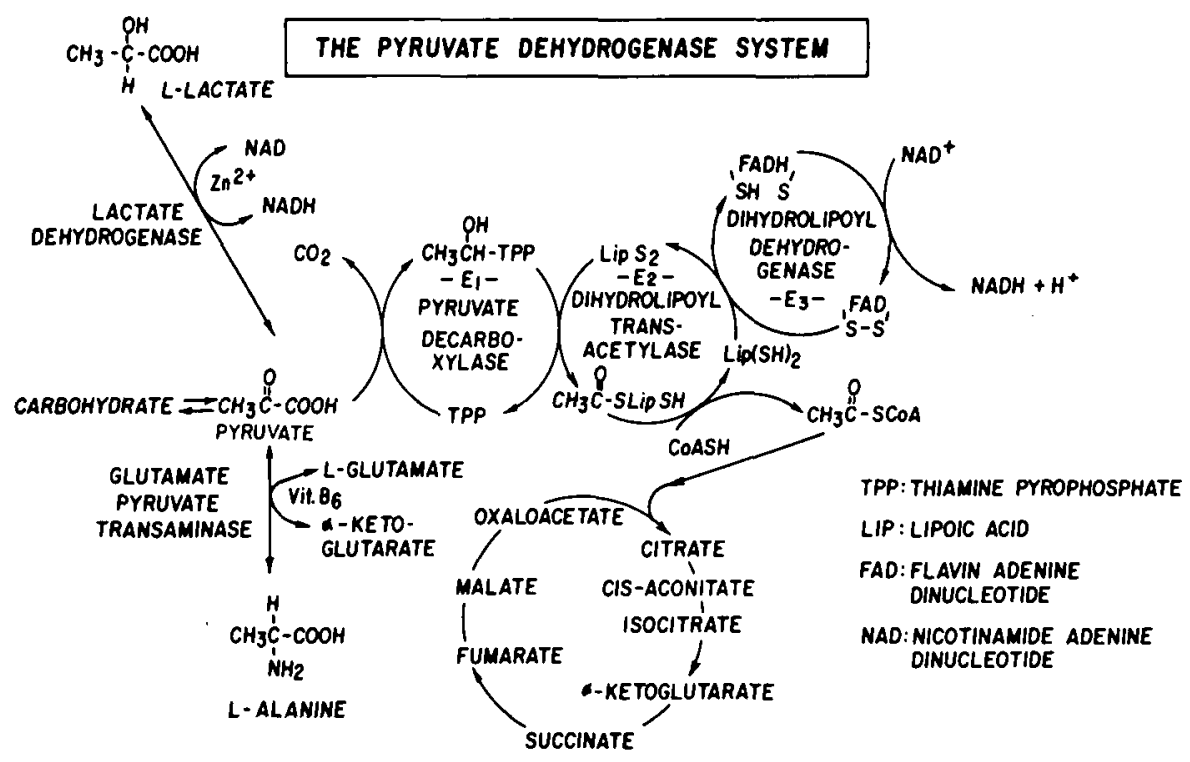

Figure 2-Pyruvate dehydrogenase complex.

\section{REGULATION OF THE PYRUVATE DEHYDROGENASE COMPLEX}

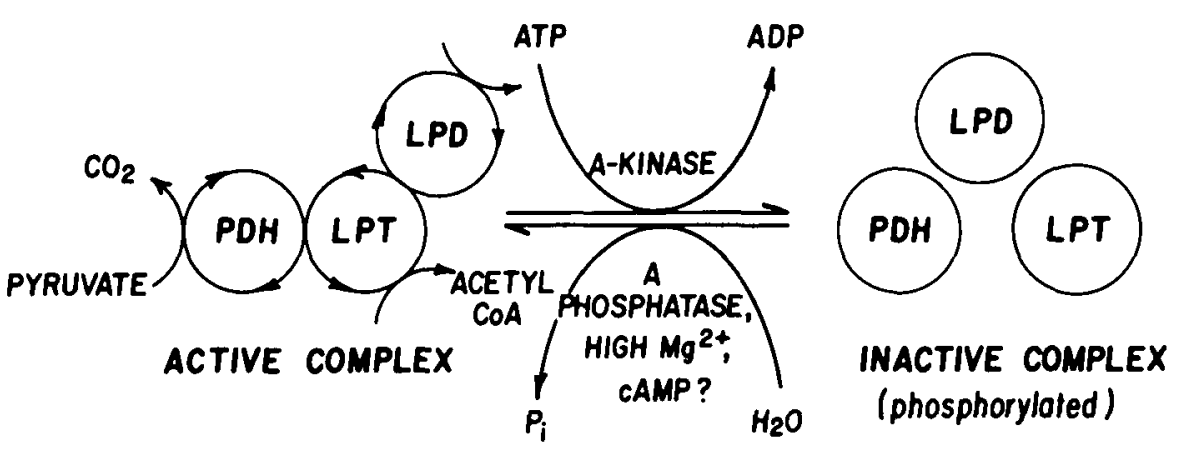

Figure 3-Regulation of pyruvate dehydrogenase complex.

whatever the cause of this bilirubin defect, it is not likely to be primarily responsible for the other abnormalities in pyruvate oxidation and glucose metabolism.

(2) Insulin Metabolism. In our patients with Friedreich's ataxia, we found an important sub-group with low fasting plasma insulin values and delayed responses to a glucose load. In most of these patients, an abnormal pyruvate response and glucose tolerance test were also found. It would appear that these selected patients, who often had clinically evident diabetes, either did not release insulin properly from metabolic stress, or had unresponsive insulin receptors. As reported (Wieland and Weiss, 1971; Weiland, 1972), insulin can, through its modification of free fatty acids and acetyl co-enzyme A, regulate the rate of oxidation of pyruvate. Insulin can also modify the rate of transport of a variety of amino acids across membranes. A primary defect in insulin release (calcium mediated?) could account for a number of the metabolic findings in Friedreich's ataxia (insulin dependence, clinical diabetes, glucose intolerance, slow pyruvate oxidation and possibly also some of the amino acid abnormalities). However, not all typical patients with Friedreich's ataxia show a defect in insulin metabolism. Sixty percent of the patients had normal fasting insulin levels and at least $30 \%$ had normal responses to a glucose challenge. It is unlikely that the insulin defect is primary in this disease. Furthermore, it does not appear to be specific as other groups of ataxias (Groups Ib, IIa, IIb) also show some abnormalities.

(3) Pyruvate Metabolism. Patients with Friedreich's ataxia demonstrate, in vivo, a slow oxidation rate of pyruvate in answer to a glucose challenge. This trait, which appears to be inherited, does not affect all cases of Friedreich's, but only an important sub-group. Others, with the same phenotype, do not respond in an abnormal manner. This pyruvate defect has been found in other ataxias and in a number of chronic neuropathies (Joiner, 1950; Collis and Engel, 1968). It is not 
TABLE 1

Comparison of Findings in Friedreich's Ataxia

Between Recent Literature Reviews and Present Prospective Survey

\section{LITERATURE REVIEWS}

Refs.: 1. Tyrer (1975)

2. Lubozynski and Roelofs (1975)

\section{A) CLINICAL}

a) Genetic

(i) - mostly recessive

- occasionally dominant

- possibility of mixture dominant and recessive

- rare sex-linked recessive

b) Sex incidence

(i) Predominance of women to predominance of males to equal distribution

c) Age of onset

(i) Onset before puberty usually range 0-30 years

d) Diagnostic - Clinical signs

\section{PRESENT PROSPECTIVE SURVEY}

Patients from Group Ia

("typical"' Friedreich's ataxia)

a) Genetic

(i) Always autosomal recessive

b) Sex incidence

(i) From retrospective study and calculations: equal distribution

(ii) In prospective study: predominance of women (probably selection artefact)

c) Age of onset

(i) Onset before puberty

- never after age 20

- never congenital

d) Diagnostic - Clinical signs

\section{OBLIGATORY SIGNS}

(i) Ataxia of gait early sign

(ii) Speech disturbances: early sign - staccato and explosive

(iii) Progression of ataxia to upper limbs with or without without periods of remission

(iv) Muscle weakness frequent with or without hypotonia.

(v) Decreased vibratory and/or position sense: usual

(vi) Deep tendon reflexes usually absent or decreased, but but can be overactive.

(i) Pes cavus (claw foot) - in most patients

(ii) Kyphoscoliosis - from absent to very severe

(iii) Cardiomyopathy variable in incidence from 10 to $73 \%$ from history, and clinical signs

Pathological evidence of cardiomyopathy at autopsy may approach $100 \%$

(iv) Babinski sign: extensor plantar response usually present (i) Obligatory for diagnosis

(ii) Obligatory for diagnosis

(iii) Progression obligatory. No remissions or plateaus.

(iv) Muscle weakness always present. Generally hypotonic.

(v) Decreased vibratory and/or position sense always present in lower limbs, usual in upper limbs.

(vi) Deep tendon reflexes always absent in lower limbs; decreased or absent in upper limbs; never exaggerated

\section{PROGRESSIVE SIGNS}

(i) Present in more than $90 \%$ of cases - progressive from year to year - not obligatory for diagnosis.

(ii) Present (minimum $10^{\circ}$ ) in all cases within first 2 years of evolution

(iii) Cardiomyopathy present in nearly $100 \%$ of cases when results of clinical examination, EKG, vectocardiograms and echocardiograms are combined

Same

(iv) Extensor plantar response always present within 2 years from onset of ataxia 
TABLE 1 (continued)

III. ACCESSORY SIGNS

(i) Intelligence is usually within normal limits

(ii) Optic atrophy: variable incidence

(iii) Autonomic changes: variable incidence

(iv) Nystagmus: Variable incidence

(v) Deafness and vestibular signs: variable incidence

\section{B) PARACLINICAL}

a) Pulmonary function

Variable evidence of involvement

b) Electrocardiography and other cardiac investigations: See above under cardiomyopathy. Signs irregularly present, but frequent.

c) Electroencephalography

Possibility of abnormal rhythms, inconstant

d) Electromyography

Slight reduction in motor conduction velocities and amplitude of muscle action potentials

\section{C) Pathology}

(i) Mainly posterior roots \& columns, Clarke's column, the spinocerebellar tracts and pyramidal tracts

(ii) Dying back phenomenon selectively from large neurone cell bodies in posterior nerve roots, ganglia and large myelinated axones. Preservation of fine unmyelinated nerve fibres.

\section{D) BIOCHEMISTRY}

a) Glucose metabolism
(i) Clinical evidence of "diabetes" present in 8-18\% of patients
(ii) "Chemical" diabetes (abnormal glucose tolerance test) frequent

(iii) Insulin response to glucose not studied (i) Definite evidence of progressive intellectual impairment, especially in patients with clinical or chemical diabetes

(ii) Same

(iii) Same

(iv) Same

(v) Deafness seems to be a progressive sign; vestibular instability is fairly frequent

a) Pulmonary function

Progressively impaired in parallel with progression of kyphoscoliosis

b) Electrocardiography and other cardiac investigations: Preference expressed for vectocardiograms and echocardiograms as investigative techniques. Both show unusual and perhaps characteristic features of hypertrophic cardiomyopathy with occasional obstructive component

c) Electroencephalography

Variable abnormal rhythms ranging to frank epilepsy. No diagnosis feature, but evidence for suprabulbar involvement in many patients

d) Electromyography

(i) Motor conduction velocities usually normal or only slightly reduced (never by more than $15 \%$ from lower limit of normal).

(ii) Sensory evoked potentials and conduction velocities generally completely absent in lower limbs, considerably reduced (to less than $10 \%$ of normal) elsewhere

(iii) EMG - very slight modifications

(i) Same

(ii) Same

a) Glucose metabolism

(i) Clinical diabetes in approximately $20 \%$ of patients

(ii) "Chemical" diabetes in a further $20-30 \%$ of patients

(iii) Frequently abnormal insulin response (in more than $60 \%$ of cases) to glucose load. Frequently low fasting insulin levels 
TABLE 1 (continued)

(iv) Pyruvate metabolism: not studied

(v) Enzymes of carbohydrate metabolism: Decreases or absent activities of glycolytic enzymes in Clarke's column; occasional elevations (33\%) of aldolase and transaminases

b) Lipid Metabolism

(i) No changes in Friedreich's ataxia, but some phenotypically similar entities in Refsum's disease (phytanic acid), $\alpha$-or hypobetalipoproteinemias.

\section{c) Amino acid metabolism}

(i) In spinal cord: abnormally low levels of aspartic and and glutamic acids and lowered leucine/isoleucine value - Findings probably unspecific

(ii) Serum and urine amino acids little studied, but apparently normal

d) Miscellaneous

(i) Serum ceruloplasmin: occasionally low

(ii) Bilirubin metabolism: No data available (iv) Clearly abnormal response of pyruvate to glucose load indicating slow pyruvate oxidation - parallel response of lactate

(v) Normal serum values of most enzymes of glycolytic pathway except as indicated above (in vivo) for pyruvate dehydrogenase

\section{b) Lipid Metabolism}

(i) Same. Lipid immuno-electrophoresis normal. No abnormality in phytanic acid; no acanthocyotsis. Serum phospholipids normal in quantity and composition

c) Amino acid metabolism

(i) No study carried out on spinal cord tissues

(ii) - Serum and mainly urinary alanine levels elevated (overflow?)

- Low CSF taurine and aspartic acid levels

- Low serum, but normal urinary levels of aspartic acid

- Normal serum, but considerably increased levels of urinary taurine with abnormally high renal clearances of taurine (possible tubular reabsorption defect)

- High urinary excretion of $\beta$-alanine and $\beta$-aminoisobutyric acid (BAIB)

d) Miscellaneous

(i) Normal values of serum ceruloplasmin

(ii) Frequent occurrence (in at least one sub-group) of elevated unconjugated bilirubinemia with day to day variability, increases after fasting, and essentially normal liver function tests. Apparently responsive to taurine availability specific. Even in the patients manifesting the trait ("high pyruvate responders"), this was evident only in the in vivo tests. Studies of the $E_{1}$, $E_{2}, E_{3}$, components of pyruvate dehydrogenase $(\mathrm{PDH})$ failed, during in vitro investigations in leukocytes or cultured fibroblasts, to reveal marked changes, except possibly in E. (lipoamide dehydrogenase, LAD). Evidence reviewed in a previous paper indicates that if a defect exists, it is only present in the regulatory control of $\mathrm{PDH}$, or more specifically, of LAD. It does not appear to be of sufficient magnitude and constancy (except in very rare cases such as those outlined by Blass et al., 1976) to be due to a protein mutation in the apoenzyme moiety of LAD. We postulated a binding defect of FAD or NAD on the lipoamide dehydrogenase molecule, possibly calcium or pyridoxal phosphate mediated (see discussion in previous paper) (figures 2 and 3 ).

Whatever the primary importance of a PDH defect, if present, it can explain a number of findings in Friedreich's ataxia. A slow pyruvate oxidation would account for abnormal pyruvate values after a glucose challenge. Lactate and enzyme LDH would be expected to be high (which they are in some cases) and there should be an overflow of alanine into the urine (which was found). Similarly the decreased availability of acetyl co-enzyme A (acetyl Co A) could be reflected in a cholinergic deficit, as demonstrated by Gibson et al. (1975). Although this point has not been investigated, a block in the
PDH pathway could result in overuse of the direct pyruvate to acetoacetate pathway, drawing into the Krebs Cycle, to keep it active, aspartic acid and asparagine. Both were found in low concentrations in the plasma of our patients. Finally, as discussed by Reynolds and Blass (1976), impairment of pyruvate flow would tend to be particularly manifest in the cerebellar-brain stem area where pyruvate metabolism is naturally slower. This could be a factor in the gait ataxia of all these subjects. It is, however, difficult to tie-in a PDH deficiency to the observed changes in the metabolism of bilirubin and taurine and to the cardiomyopathy. Therefore, we doubt that this defect, not always present, could be primary in the disease.

(4) Taurine and $\beta$-alanine 
metabolism. The most constant finding in our survey was the increased urinary excretion of taurine and $\beta$-alanine in all patients studied (including other ataxias not typically of Friedreich's type). Since plasma values were within normal limits and we found low CSF levels, the renal clearance rate of taurine was calculated to be markedly, and significantly, increased. The only other amino acid with a calculated increased clearance was aspartic acid.

Increased renal clearance rates, in the absence of overflow, generally indicate impaired tubular reabsorption, thus a membrane transport defect. It has been clearly demonstrated (Scriver and Rosenberg, 1973) that taurine, $\beta$-alanine and $\beta$-amino-iso-butyric acid (BAIB), participate in the same $(\beta$-amino acid) transport system. A specific defect in this system has been described and studied in the mouse (Goldman and Scriver, 1967; Chesney et al., 1975). It is possible that a similar defect could be found in man. Taurine has been considered an inactive compound (Jacobsen and Smith, 1968; Huxtable and Barbeau, 1976), but recent studies (Barbeau et al., 1975) indicate that it may act as an important modulator of nerve conduction in muscle, heart and the central nervous system. $\beta$-alanine, on the other hand, is metabolically active and can be synthesized directly by $\beta$-decarboxylation from aspartic acid.

If a membrane transport defect exists in the kidney alone or in all tissues in Friedreich's ataxia, this could explain many of the reported findings in this disorder. The first obvious link is related to the specific concentration of taurine to the cerebellum and to the posterior columns of the spinal cord found in animals and man (Huxtable and Barbeau, 1976; Perry et al., 1971, 1976). Taurine appears to be intimately related to sensory conduction in the spinal cord, as it is in the retina and auditory system (Pasantes-Morales et al., 1976). A decrease in its concentration could possibly explain the posterior column signs and the absent tendon reflexes found in Freidreich's ataxia.
Huxtable and Bressler (1974a, 1974b) have demonstrated marked changes in the concentration of taurine during cardiac insufficiency states with hypertrophy. Previously, Read and Welty (1976) had indicated a possible link between taurine and electrical conduction defects in the heart. Such a relationship would be important to investigate in the hypertrophic cardiomyopathy of Friedreich's ataxia. It is also noteworthy that $70 \%$ of the body taurine is concentrated in skelatal muscles. Changes in the concentration of this amino acid could be important in the reactivity of this muscle mass (resulting in progressive dystonic postures?).

It is also known that one of the most important bile salts is taurocholate, formed from the incorporation of taurine (Spaeth and Schneider, 1974). It is presently difficult to elucidate the relationship between this fact and our findings of abnor- mal 'bilirubin metabolism in some patients with Friedreich's ataxia.

Finally, taurine can be involved in the modulation of a number of hormonal interactions. Stress will release glucocorticoids which in turn will increase circulating glucose levels. This effect on glucocorticoid release can be blocked by the addition of taurine (Kuriyama et al., 1976). Similarly T. Ngo in our laboratory (unpublished results) has shown that the pyridoxal phosphate induced blocking of pyruvate dehydrogenase $(\mathrm{PDH})$ could be reversed by the addition of taurine.

The mechanism of action of taurine, and of $\beta$-alanine, are still unknown. We, and others, have shown that taurine can exert an anticonvulsive action (see Barbeau, 1975) when given intraventricularly. This may, or may not, indicate direct transmitter functions for this amino acid (Kaczmarek and Davison, 1972). Other data would indi-

\section{TABLE 2 \\ Characteristic Features of "Typical" Friedreich's Ataxia (View in 1976)}

1. Always inherited in autosomal recessive fashion.

2. Age of onset before end of puberty.

3. Ataxia first of lower limbs, then of all four limbs, progressing relentlessly without remission and always accompanied by muscle weakness.

4. Presence of dysarthria very early in the disease.

5. Absence of vibratory and/or position sense in the lower limbs.

6. Absence of deep tendon reflexes in the lower limbs.

7. Progressive development, within two years after onset, of pes cavus and kyphoscoliosis.

8. Presence of a progressive cardiomyopathy, generally of the hypertrophic type, which is best detected by a combination of vectocardiography and echocardiography.

9. Absence of sensory nerve conduction in the lower limbs with a considerable slowing down in the upper limbs.

10. An abnormality in glucose and insulin metabolism frequently resulting in clinically overt diabetes mellitus.

11. A genetically determined defect in the rate and regulation of pyruvate oxidation resulting in overflow of alanine into the urine and probably responsible for low aspartic acid levels in the brain and spinal cord.

12. An abnormal renal tubular reabsorption of $\beta$-amino acids, particularly taurine and $\beta$-alanine, indicating a possible specific membrane transport defect with consequent tissue deficiency which could be a basic contributor to many of the features of the disease.

13. At least in an important sub-group of Friedreich's ataxia patients. an elevation of plasma unconjugated bilirubin, possibly secondary to a transport defect. 
cate that one of the main modes of action of taurine is through the modulation of calcium binding (Izumi and Barbeau, 1976, unpublished data). This mechanism could be involved in almost all the processes mentioned above in Friedreich's ataxia: increased binding of calcium in low taurine states would modify the availability of free calcium for release of other neuro-transmitters or polypeptide hormones (for example insulin); it would tend to increase calcium concentration in cardiac muscle (see pathology findings in previous paper) and it would modify the activation of PDH either through TPP binding, binding of the phosphatase to the $E_{2}$ component or binding of NAD to the $E_{3}$ component. Taurine has been found to reverse the calcium depleting effect of glucose in heart and brain (Kuriyama et al., 1976) and would seem to be a calcium stabilizing agent in irritative tissues (Gruener et al., 1975).

Thus, taurine, by apparently being a regulator of calcium flux, can be implicated in almost all the metabolic abnormalities observed in Friedreich's ataxia. Although we have no direct evidence that a membrane transport defect is present in all cases of this disease, this is presently our strongest lead to the primary defect, at least in some of the patients. A number of studies are presently underway to investigate this possibility. For example, Jasmin et al. (1975) have shown accumulation of calcium in the cardiomyopathy of the hamster, and have been able to prevent this cardiopathy by pretreatment with the calcium flux blocking agent verapamil and by propanolol and/or dibenamine. Perhaps a similar approach could be justified in humans with hypertrophic cardiomyopathies.

\section{CONCLUSION}

Friedreich's ataxia is a degenerative disorder which appears to be heterogeneous in nature. It is difficult to be certain that the same biochemical defect, be it in insulin, bilirubin, pyruvate or taurine metabolism or a combination, could be involved in all cases. We found, almost always, 2 sub-groups of patients whenever we investigated a specific metabolic system. In one group, the taurine defect, and that found in bilirubin, seemed predominant with normal pyruvate oxidation. In the other group, the low pyruvate oxidation seemed to be the major metabolic component. It is possible that both manifestations are variable expressions of the same defect. Only more thorough genetic and metabolic studies will resolve this problem.

Meanwhile, as is shown in Table 1 , we have reassessed most of the clinical and biochemical components of Friedreich's ataxia. We can list, in a tentative fashion, what in 1976 we consider the characteristic features of typical Friedreich's ataxia. These are listed in Table 2. Further phases of our continuing cooperative study should help in unraveling the details of this fascinating puzzle.

\section{ACKNOWLEDGMENTS}

The studies reviewed in this paper were supported in part by grants from l'Association Canadienne de l'Ataxie de Friedreich, la Fondation Jeanne-Mance, the Medical Research Council of Canada and the W. Garfield Weston Foundation. We would like to give special thanks to Mrs. Monique Savard for typing the complete manuscript of the supplement on Friedreich's ataxia and for acting as coordinating secretary throughout the studies of Phase One.

\section{REFERENCES}

BARBEAU, A., INOUE, N., TSUKADA, Y. and BUTTERWORTH, R. F. (1975). The neuropharmacology of taurine. Life Sci., 17, 669-678.

BLASS, J. P., KARK, R. A. P. and ENGEL, W. K. (1971). Clinical studies of a patient with pyruvate decarboxylase deficiency. Arch. Neurol., 25, 449-460.

BLASS, J. P., KARK, R. A. P. and MENON, N. K. (1976). Low activities of the pyruvate and oxoglutarate dehydrogenase complexes in five patients with Freidreich's ataxia. New Engl. J. Med., 295, 62-67.

CAVANAGH, J. B. (1964). The significance of the "dying back" process in experimental and human neurological disease. Int. Rev. Exp. Path., 3, 219-267.

CHESNEY, R. W., SCRIVER, C. R. and MOHYUDDIN, F. (1975). Location of mutant $\beta$-amino acid carrier in renal epithelium. Clin. Res., 23, 650A.

COLLIS, W. J. and ENGEL, W. K. (1968). Glucose metabolism in five neuromuscular disorders. Neurology, 18, 915-925.
GIBSON, G. E., JOPE, R. and BLASS, J. P. (1975). Decreased synthesis of acetylcholine accompanying impaired oxidation of pyruvic acid in rat brain minces. Biochem. J., 148, 17-23.

GOLDMAN, H. and SCRIVER, C. R. (1967). A transport system in mammalian kidney with preference for $\dot{\beta}$-amino compounds. Pediat. Res., 1, 212-213.

GRUENER, R., MARKOVITZ, D., HUXTABLE, R. and BRESSLER, R. (1975). Excitability modulation by taurine: transmembrane measurements of neuromuscular transmission. J. Neurol. Sci., 24, 351-360.

HUXTABLE, R. and BARBEAU, A. (Eds.) (1976). Taurine, Raven Press, New York, pp. 1-398.

HUXTABLE, R. and BRESSLER, R. (1974a). Elevation of taurine in human congestive heart failure. Life Sci., 14, 1353-1359.

HUXTABLE, R. and BRESSLER, R. (1974). Taurine concentrations in congestive heart failure. Science, 184, 1187-1188.

JACOBSEN, J. G. and SMITH, L. L. H. (1968). Biochemistry and physiology of taurine and taurine derivatives. Physiol. Rev., 48, 424-511.

JASMIN, G., SOLYMOSS, B. and EU, $H$. $Y$. (1975). Effect of thyroparathyroidectomy and of a low calcium diet on the cardiomyopathy of the Syrian hamster. In: The Metabolism of Contraction, University Park Press, Baltimore (Roy, P.E. and Rona, G., Eds.), pp. 717-729.

JOHNSON, J. L. (1975). Compartmentation of $\left(\mathrm{U}-{ }^{14} \mathrm{C}\right)$ proline metabolism in the dorsal root ganglion: Contrasts with the ventral spinal cord gray and cerebral cortex. Brain Res., 96, 192-196.

JOHNSON, J. L. (1976). A comparative analysis of compartmentation of metabolism in the dorsal root ganglion and ventral spinal cord gray using $\left(\mathrm{U}^{-14} \mathrm{C}\right)$ glucose, $\left(2^{-14} \mathrm{C}\right.$-) glucose, $\left(6^{-14} \mathrm{C}\right)$ glucose, $(3$, $\left.4-{ }^{14} \mathrm{C}\right)$ glucose, $\mathrm{NaH}^{14} \mathrm{CO} 3$, and $\left(2 .{ }^{14} \mathrm{C}\right)$ pyruvate. Brain Res., 101, 523-532.

JOINER, C. L., MCARDLE, B. and THOMPSON. R. H. S. (1950). Blood pyruvate estimations in diagnosis and treatment of polyneuritis. Brain, 73, 431-452.

KACZMAREK, L. K. and DAVISON, A. N. (1972). Uptake and release of taurine from rat brain slices. J. Neurochem., 19, 2355-2362.

KURIYAMA, $K$. and NAKAGAWA, K. (1976). Role of taurine in adrenal gland: $A$ preventive effect on stress-induced release of catecholamines from chromaffin granules. In: Taurine, (Huxtable, R. and Barbeau, A., Eds.). Raven Press, New York, pp. 173-177.

LUBOZYNSKI, M. F. and ROELOFS, R. I. (1975). Friedreich's ataxia. Southern Med. J., 68, 757-763.

PASANTES-MORALES, H., SALCEDA, R. and LOPEZ COLOMBE, A. M. (1976). The role of taurine in retina: Factors affecting its release. In: Taurine, (Huxtable, $R$. 
and Barbeau, A., Eds.), Raven press, New York, pp. 191-200.

PERRY, T. L., BERRY, K., HANSEN, S،, DIAMOND, S. and MOK, C. (1971). Regional distribution of amino acids in human brain obtained at autopsy. J. Neurochem., 18. 513-519.

PERRY, T. L., MacLEAN, J., PERRY, T. L. (jr.) and HANSEN, S. (1976). Effect of 3-acetyl pyridine on putative neurotransmitter amino acids in rat cerebellum. Brain Res., 109, 632-635.

POWELL, L. W., HEMINGWAY, E., BILLING, B. H. and SHERLOCK, S. (1967). Idiopathic unconjugated hyperbili- rubinemia (Gilbert's syndrome) - A study of 42 families. New Engl. J. Med., 23, $1108-1112$.

READ, W. O. and WELTY, J. D. (1976). Effect of taurine on the action potential of guinea pig capillary muscle. In: Taurine, (Huxtable R. and Barbeau, A.. Eds.), Raven Press, New York, pp. 173-177.

REYNOLDS, S. F. and BLASS, J. P. (1976). A possible mechanism for selective cerebellar damage in partial pyruvate dehydrogenase deficiency. Neurology. 26,625-628.

SCRIVER, C. R. and ROSENBERG. L. E. (1973). Amino acid metabolism and its dis- orders. In: Major Problems in Clinical Pediatrics, Vol. 10. W. B. Saunders Co.. Philadelphia, pp. 1-491.

SPAETH, D. G. and SCHNEIDER. D. L. (1974). Taurine synthesis, concentration and bile salt conjugation in rat, guinea pig and rabbit. Proc. Soc. Exp. Biol. Med.. 147-855-858.

TYRER, J. H. (1975). Friedreich's ataxia. In: Handbook of Neurology. Vol. 22. (Vinken and Bruyn, eds.), pp. 319-364.

WIELAND, O., HELMREICH, E. and HOLZER, H. (Eds.) (1972). Metabolic Interconversion of Enzymes. Springer Verlag, Heidelberg. 